\title{
Prevalence of depression and its risk factors among a rural geriatric population of North Kerala
}

\author{
Rose Jacob S. ${ }^{1 *}$, Rapheal L. ${ }^{2}$, Bina T. ${ }^{3}$ \\ DOI: https://doi.org/10.17511/ijphr.2015.i4.05 \\ 1* Sabitha Rose Jacob, Assistant Professor, Department of Community Medicine, Government Medical College, Manjeri, Kerala, India. \\ 2 Lucy Rapheal, Professor, Department of Community Medicine, Government Medical college, Manjeri, Kerala, India. \\ 3 Thomas Bina, Professor, Department of Community Medicine, Government Medical college, Manjeri, Kerala, India.
}

Introduction: Depression in elderly is a common and important health problem causing considerable morbidity and disability. But it is often undetected and neglected as a normal part of aging. Methods: In order to studythe prevalence of depression and its risk factors among rural elderly population a cross sectional study was conducted in the field practice area of Community Medicine department of a tertiary care center of North Kerala. The study population was selected by cluster sampling technique. Data on socio demographic characteristics and morbidity were collected using personal interview schedule. Psychological morbidity was assessed using Geriatric Depression Scale (GDS 15) and elderly cognitive assessment questionnaire(ECAQ). Results: Among a study population of 395 , a total of $230(58.2 \%)$ had some depression. Females and those with a poor perception of health had higher prevalence. Presence of a chronic morbidity OR=1.3 95\%CI (1.021.68), cognitive impairment $\mathrm{OR}=1.2,95 \% \mathrm{CI}(1.02-1.42)$, physical disability, unmarried statusOR$1.01,95 \% \mathrm{CI}(.85-1.38)$, being illiterate OR=1.29 $95 \% \mathrm{CI}(1.09-1.52)$ and staying alone OR=1.3 95\% CI (0.96-1.75)were the risk factors found to be significantly associated with depression. Conclusions: Prevalence of depression is high among rural geriatric population and it is associated with risk factors like chronic morbidity, physical disability and low socio economic status which can be managed by timely interventions. Appropriate social and health measures are needed to improve the quality of life of elderly.

Keywords: Depression, Elderly, Risk Factors

\section{Corresponding Author}

Sabitha Rose Jacob, Assistant Professor, Department of Community Medicine, Government Medical College, Manjeri, Kerala, India. Email: sabitha1020@gmail.com

\section{How to Cite this Article}

Jacob SR, Rapheal L, Bina T. Prevalence of depression and its risk factors among a rural geriatric population of North Kerala. Public Health Rev Int J Public Health Res. 2015;2(4):49-55. Available From https://publichealth.medresearch.in/index.php/ijphr/ article/view/19
To Browse

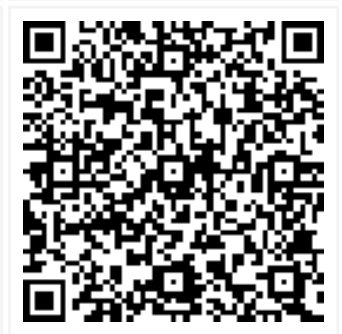

Manuscript Received 2015-10-28

Conflict of Interest No (c) 2015 by Sabitha Rose Jacob, Lucy Rapheal, Thomas Bina and Published by Siddharth Health Research and Social Welfare
Society. This is an Open Access article licensed under a Creative Commons Attribution 4.0 International License https://creativecommons.org/licenses/by/4.0/ unported [CC BY 4.0].
hen 4 .

Accepted 2015-12-03 2015-11-10 unding (1) 


\section{Introduction}

World population is aging. Along with globalization population aging too is a concern of 21 st century [1]. Generalized trend of decline in mortality and decline in fertility have led to increased life expectancy. Our concern about increased longevity is this: what will these added years bring? Will they be spent in active, productive fulfilling endeavors, or will they be overshadowed by declining health, loss of memory and lingering illness[2].

Population aging has got major social and health implications also. Among a global population of 600 million elderly, many are suffering from chronic morbidities, both physical and psychological. Though depression can occur at any age, it is the most common mental disorder among elderly [3]. Depression is perhaps the most frequent cause of emotional suffering in later life and significantly decreases the quality of life in older adults [4]. Global burden of disease study showed that depression will be the second most leading cause of DALY's by 2020 in developing world [5].

Prevalence rates of depression is high among hospitalized in patients, ranging from $10 \%$ to $45 \%$ with an average of about $15 \%$ and the diagnosis is frequently missed by hospital physicians. Depression leads to reduced life satisfaction, social deprivation, loneliness, increased use of health and home care services, cognitive decline, impairments in activities of daily living, suicide and increased non suicide mortality [6].

Symptomatically depression is a disorder which is characterized by sadness, changes in appetite, altered sleep pattern, feeling dejection or hopelessness and sometimes suicidal tendencies. But it is not a normal or necessary part of aging process. In the geriatric age group it may not present with typical symptoms and it can occur due to genetic predispositions, negative life events and chemical imbalances, use of therapeutic and recreational drugs. Depression in elderly is so often over looked.

Early diagnosis is important for a better outcome. Community level assessment of depression can be done using various depression scales. GDS 15 is a short scale, which at a cut off of 5 gives optimal best sensitivity (71.8\%) and specificity (78.2\%) [7]. Pooled studies of GDS-15 indicated a sensitivity of $80.5 \%$ and specificity of $75 \%$ with optimal cut off $5 / 6$ [8].
Depressive disorder was the most common psychiatric morbidity among the elderly patients [9]. Just like other non-communicable disease depression too has various risk factors [10]. It seems to be associated with female gender, low family income, lack of social support, relationship problems, poor health status, adverse events in the past 2 years. Risk factors leading to the development of late life depression likely comprise complex interactions among genetic vulnerabilities, cognitive diathesis, age-associated neurobiological changes, and stressful events [11].

\section{Materials and Methods}

A cross sectional study was conducted in Peruvayal Panchayath area of Kozhikode district of North Kerala. Peruvayal is one of the 78 panchayaths of the district having 9447 households, $7.8 \%$ of population above 60 years. According to NSSO 58th round, prevalence of reported morbidity among geriatric population was taken as $58 \%$. With design effect of 1.4 sample size was estimated to be 418 and the numbers of clusters required were 10. From 22 wards, 10 wards were selected as clusters. The data were collected using semi-structured schedule.

The semi structured schedule consisted of two parts: Part A consisted of socio demographic variables like age, sex, education, marital status and socio economic variables like income and details on morbidity. Socio economic status was assessed by using Udai -Pareeks scale [12]. Prevalence of morbidity was assessed on the basis of participant's treatment reports of previously diagnosed diseases. Part B consisted of Geriatric Depression Scale (GDS15), Barthel Index on Activities of Daily Living and Elderly Cognitive Assessment Questionnaire (ECAQ).

The geriatric Depression Scale (GDS-15) created by Yegavage et al has been tested and used extensively to measure depression among the elderly[13],[14]. It is a brief questionnaire that consists of 15 questions. Scores of more than 5 indicates presence of depression, and scores of 4 or less are considered to be negative for depression. Scores 5-8 are categorized as mild depression, 9-11 as moderate and $12-15$ as severe depression.

Barthel Index on Activities of Daily Living (BIADL) was introduced to follow the progress in self-care and mobility skills of patients during rehabilitation [15]. This questionnaire has been validated in the evaluation of functional status among elderly. 
The questions of the Barthel Index consists of 10 items of Activities of daily Living (ADL) such as feeding, dressing, grooming, bathing, control of urinary bladder, control of bowel, transfer to bed, using toilet, mobility on level surface and climbing stairs.

A respondent is categorized to have normal function in doing an activity if he or she can perform all 10 activities independently, A respondent is categorized as having 'functional disability ' when he or she has difficulty or needs help in performing one or more of the activities.

Elderly Cognitive Assessment Questionnaire (ECAQ) a 10 item questionnaire was introduced by Kua et al [16]to evaluate for cognitive impairment among elderly in developing countries. Respondents are categorized as normal in the cognitive assessment when their ECAQ scores were 6 or above. Scores of 5 and below were considered to be cognitively impaired.

Data were analyzed using SPSS software Chi square test was used to find statistical significance. The level of significance was fixed at $p$ value $=0.05$. Odds Ratio and 95\% CI was used to assess risk factors.

\section{Results}

Out of 403eligible population, 395 including $127(32.2 \%)$ males and $268(67.8 \%)$ females participated in psychological morbidity assessment. The age category wise distribution of the population was $57.2 \%$ in young old category (60-69 yrs.),30.5\% in old old category (70-79 yrs) and $12.3 \%$ in oldest old $(80+$ yrs.). Mean age was $70.97 \pm 8.55$ yrs. for males and $68.02 \pm 7.4$ for females.

Socio demographic Characteristics of the population: Among the study population majority (58\%) belonged to Hindu religion.23\% were illiterate.55.4\% of the elderly were currently married. A high proportion of females (53.3\%) were widows.95.9\% of the population was staying with family or relatives. But $4.1 \%$ were staying all alone in their old age.184 (47.2\%) were having no income at all. Those who had some income, it was less than Rs. 500per month for majority. Using Modified Udai Pareek scale majority of the population were either in low socio economic status (50.1\%)or middle class (45.6\%).Only $4.3 \%$ of the elderly could be categorized as high class.
Morbidity among Study Population: At the time of study 313 (80.3\%) elder persons reported having at least one chronic morbidity. Major proportion of the morbidity was contributed by non-communicable diseases, which include diabetes mellitus, hypertension, ischaemic heart disease, breathlessness, joint symptoms, cancer etc. Many were having more than one morbidity. 32\% had two diseases and $7.2 \%$ has three diseases. The major morbidities and its prevalence are shown in fig1.

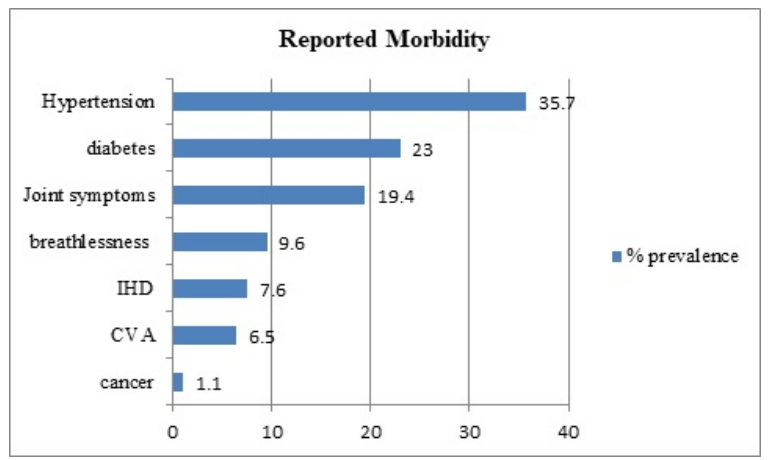

Prevalence of Depression and Risk Factors: Among the study population 230 had some depression. Prevalence of mild, moderate and severe depression were $28.9 \%, 22.6 \%$ and $6.6 \%$ respectively as shown in table 3. Mean GDS score was $5.96 \pm 2.76$.Scores more than 5 were graded as having depression. According to BIADL 33(8.5\%) had physical disability. Mean score was $19.69 \pm 1.5$. By using ECAQ, cognitive impairment was present for 124 persons $(31.8 \%)$. The mean score was $5.99 \pm 2.3$.

Depression can occur at any age in the geriatric age group, and there can be many precipitating factors. Loneliness, financial dependence, physical disability, chronic diseases or pure mental deterioration due to aging can lead to depression. In this study, prevalence of depression was higher among females (59.3\%) compared to males (55.7\%). In young old category $56 \%$ had depression. In old old group $66 \%$ and oldest old group 58\% had depression. Prevalence of depression was higher among those having a physical disability (10.4\%) compared to those without disability(5.5\%). Among those living alone $5.2 \%$ had depression compared to $2.4 \%$ among those lived with family. With all the above risk factors these differences had no statistical significance ( $p$ value was $>0.05$ )

Among illiterate elderly the prevalence of depression was higher $(27.8 \%)$ compared to $16.4 \%$ among those with some education. 
The difference was statistically significant ( $p$ value $=.008$ ). belonging to a low socio economic status was another risk factor significantly associated with depression ( $p$ value $=0.011$ ). In the study population, majority perceived themselves to be in average health status (56.2\%) and $21.5 \%$ perceived their health status as poor. Having a poor perception on individual health status was significantly associated with higher prevalence of depression ( $p$ value=0.000). The risk factors and their statistical significance levels are given in following table 4.

Table 1: Age Category and Sex Distribution of the Study Population

\begin{tabular}{|l|l|l|l|}
\hline \multicolumn{1}{|c|}{ Age Category } & \multicolumn{1}{|c|}{ Male (127) } & \multicolumn{1}{|c|}{ Female (268) } & \multicolumn{1}{|c|}{ Total(395) } \\
\hline Young old & $68(48 \%)$ & $165(61.6 \%)$ & $226(57.2 \%)$ \\
\hline Old old & $44(34.6 \%)$ & $77(28.7 \%)$ & $121(30.6 \%)$ \\
\hline Oldest old & $22(17.3 \%)$ & $22(9.7 \%)$ & $48(12.2 \%)$ \\
\hline
\end{tabular}

Table-2: Distribution of Sociodemographic Characteristics of the Study Population

\begin{tabular}{|l|l|l|l|}
\hline \multicolumn{2}{|c|}{ Socio demographic Factors } & Frequency & Percentage \\
\hline \multirow{3}{*}{ Religion } & Hindu & 229 & $58 \%$ \\
\cline { 2 - 4 } & Muslim & 152 & $38.5 \%$ \\
\cline { 2 - 4 } & Christian & 14 & $3.5 \%$ \\
\hline Socioeconomic status & Low & 198 & $50.1 \%$ \\
\cline { 2 - 4 } & Middle & 180 & $44.6 \%$ \\
\cline { 2 - 4 } & High & 17 & $4.3 \%$ \\
\hline Education & Illiterate & 91 & $23 \%$ \\
\cline { 2 - 4 } & Literate & 304 & $77 \%$ \\
\hline Marital status & Married & 219 & $55.4 \%$ \\
\cline { 2 - 4 } & Widowed /divorced & 176 & $44.6 \%$ \\
\hline \multirow{2}{*}{ Living arrangement } & Nil & 188 & $47.6 \%$ \\
\cline { 2 - 4 } & Living alone & 16 & $4.1 \%$ \\
\cline { 2 - 4 } & Living with family & 379 & $95.9 \%$ \\
\hline
\end{tabular}

Table 3: Prevalence of Depression

\begin{tabular}{|l|l|l|l|}
\hline & Category & Frequency & \multicolumn{1}{|c|}{ Percentage } \\
\hline \multirow{3}{*}{ Depression } & Mild & 114 & $28.9 \%$ \\
\cline { 2 - 4 } & Moderate & 90 & $22.6 \%$ \\
\cline { 2 - 4 } & Severe & 26 & $6.6 \%$ \\
\hline No depression & & 165 & $41.8 \%$ \\
\hline
\end{tabular}

Table 4: Risk Factors for Depression and Statistical Significance

\begin{tabular}{|c|c|c|c|c|}
\hline Risk Factor & $\begin{array}{l}\text { Prevalence among those who had } \\
\text { depression }(n=230)\end{array}$ & $\begin{array}{l}\text { Prevalence among those who had nodepression } \\
\qquad(\mathrm{n}=165)\end{array}$ & $\left|\begin{array}{c}p \\
\text { value }\end{array}\right|$ & OR $(95 \% \mathrm{CI})$ \\
\hline Illiteracy & $64(27.8 \%)$ & $27(16.4 \%)$ & $0.008 *$ & $\begin{array}{l}1.29(1.09- \\
1.52)\end{array}$ \\
\hline Living alone & $12(5.2 \%)$ & $4(2.4 \%)$ & 0.165 & $1.3(0.96-1.75)$ \\
\hline Low SES & $130(56.5 \%)$ & $68(41.2 \%)$ & $0.011 *$ & \\
\hline Female gender & $159(69.1 \%)$ & $109(66.1 \%)$ & 0.51 & $1.01(.85-1.38)$ \\
\hline Unmarried status & $114(49.6 \%)$ & $62(37.6 \%)$ & $0.018 *$ & $1.3(1.05-1.7)$ \\
\hline Cognitive impairment & $81(35.2 \%)$ & $42(25.5 \%)$ & $0.039 *$ & $1.2(1.02-1.42)$ \\
\hline Any chronic morbidity & $193(83 \%)$ & $123(74.5 \%)$ & $0.022 *$ & $1.3(1.02-1.68)$ \\
\hline Physical disability & $24(10.4 \%)$ & $9(5.5 \%)$ & 0.078 & $1.28(1.02-1.6)$ \\
\hline $\begin{array}{l}\text { Poor Perception of } \\
\text { health }\end{array}$ & $67(29.1 \%)$ & $18(10.9 \%)$ & $0.000 *$ & \\
\hline
\end{tabular}

*Statistically significant $p$ value $<0.05$

\section{Abbreviations}

GDS: Geriatric Depression Scale

DALY: Disability Adjusted Life Years

BIADL: Barthel's Index on Activities of Daily Living

ECAQ: Elderly Cognitive Assessment Questionnaire

IHD: Ischaemic Heart Disease

CVA: Cerebro Vascular Attack

OR: Odds Ratio

\section{CI: Confidence Interval}

The single status due to widowhood, separation or being unmarried was an important risk factor for developing depression in old age. In the study population among those who were living alone $(n=15)$, majority had depression $(n=12)$. Being diagnosed with a chronic disease that requires lifetime treatment is a risk factor for depression. Having a physical disability and inability to perform activities of daily living also is found to be significantly associated with depression. Depression was found more among those without education. For all above listed factors Odds ratio and (95\% CI was within limits of significance level. 


\section{Discussion}

Most of the times, depression in elderly is missed out or overlooked, as clinical presentations of depression may be misinterpreted as problems of aging. It is always necessary to look for depression in any old person presenting to a clinical setting, to start early management and prevent its complications. Screening methods like Geriatric Depression scale can be used to detect depression in population and population based studies are necessary to estimate the true burden of depression in elderly.

Our study revealed a prevalence of $58.2 \%$ for depression among geriatric population. Prevalence of severe depression was $6.6 \%$. Prevalence of depression was varying widely in different studies. Prevalence of depression in Caucasian elderly population in west varies from $1 \%$ to $42 \%$.[17] KeeLeeet al[18] study using 8 as cut off point for 15 item Geriatric Depression Scale observed that prevalence rate was greater in oldest old $31.1 \%$ than for young old (19.1\%).

In a comparative study by Zivin $\mathrm{K}$ et al[19] using eight item Center for Epidemiologic Studies Depression Scale, observed depression was more prevalent in English than US adults (17.6\% versus $14.6 \%)$. Ather $M$ et al[20]reported a prevalence of $19.8 \%$ among Karachi Population. Among Chinese immigrants to Canada the prevalence was $23 \%$ [21].

In a community sample of India prevalence of depression varied from $6 \%$ to $30 \%$ [22]. Though it cannot be equated to depression, $47.9 \%$ elderly in Karnataka were not happy in life according to Lena etal [23]. In our study the prevalence is found to be high as the study populations being a rural one the socio economic factors are unfavorable. And they were relatively 'young' old population with higher proportion of females.

In our study depression is associated with risk factors like illiteracy, unmarried status, low socioeconomic status having a chronic morbidity, poor perception of one's own health, cognitive impairment and physical disability. Many studies reported more or less similar risk factors. A qualitative meta-analysis by Martin G Cole et al[24] revealed the risk factors for depression by univariate and bivariate analysis as disability, new medical illness, poor health status and bereavement.
According to Mitchell A J[25] older patients and patients with late onset depression are at increased risk of medical co morbidity. Medical comorbidity is a risk factor for inferior treatment response and poor antidepressant tolerability. David J Vinkers [26] also reported that depressive symptoms were significantly correlated with lower scores for global cognitive function.

In our study even though more females had depression, it was not statistically significant. Similarly increasing age was not associated with depression. Prevalence of depression was $44.8 \%$ (51.0\% women, $39.6 \%$ men) and with relation to age, gender, literacy and economic status, there were significant differences observed in a South Indian study [27]. Nuclear family system, female gender, being unmarried, unemployment and having a low level of education were the common risk factors observed in Asian population.

In conclusion, it is found that epidemiologic transition has reached the rural population also. The major disease burden reported among study population is non-communicable diseases like diabetes, hypertension, cardiovascular disease etc. Prevalence of depression is also high. The well known risk factors of depression namely poor perception of health, presence of a chronic morbidity, poor socioeconomic status and illiteracy are found among this population also.

In Sir James Sterling Ross's words "You do not heal old age, you protect it, you promote it[28]. We have to protect the life of our elderly. Financial insecurity is a major problem among rural elderly, even affecting the treatment of chronic diseases and managing physical disability. Increased life expectancy and long duration of widowhood is another disadvantage for elderly females making them at need of social support.

Depression can be precipitated by these factors or a chronic morbidity may be worsened by depression. Risk assessment and targeting of intervention strategies to prevent depression in late life should incorporate changes in functional capacity, mental status and need for residential care[29]. There is an urgent need to create awareness on geriatric morbidity among both health care system and social welfare system. A multilevel approach including age friendly health infrastructure development, social security measures, residential care homes, free treatment etc. are required to manage geriatric morbidity among rural population. 


\section{Reference}

01. WHO. Towards age-friendly primary health care. 2004.

[Crossref]

02. Nadine R, Shahyoun, Harold Lentzner, Donna Hoyert, et al. Trends in Causes of Death Among Elderly. Centers for Disease Control and Prevention National Center for Health Statistics, Ageing trends No1. March 2001.

[Crossref]

03. Sherina MohdSidi k,Nor Alfiah mohd zulkefl, Shamsul Azhar Shah. Factors associated with depression among elderly patients in a primary health care clinic in Malasiya. Asia Pacific Family Medicine. $2003 ; 2 ; 148-152$.

[Crossref]

04. Blazer DG. Depression in late life- review and commentary. J Gerontol A Biol Sci Med Sci. 2003 Mar;58(3)249-65.

[Crossref]

05. Christopher J L Murray, Alan D Lopez. Summary- The global burden of disease. Boston (MA) Harward School of Public Health. 1996.

[Crossref]

06. Khattri JB, Nepal MK. Study of depression among geriatric population in Nepal. Nepal Med Coll J. 2006 Dec;8(4)220-3.

[Crossref]

07. Marc LG, Raue PJ, Bruce ML. Screening performance of the 15 -item geriatric depression scale in a diverse elderly home care population. Am J Geriatr Psychiatry. 2008 Nov;16(11)91421.

doi: 10.1097/JGP.0b013e318186bd67 [Crossref]

08. Wancata J, Alexandrowicz R, Marquart B, Weiss $M$, Friedrich $F$. The criterion validity of the Geriatric Depression Scale- a systematic review. Acta Psychiatr Scand. 2006 Dec;114(6)398-410. [Crossref]

09. Thapa P, Chakraborty PK, Khattri JB, Ramesh K, Sharma B. Psychiatric morbidity in elderly patients attending OPD of tertiary care centre in western region of Nepal. Ind Psychiatry J. 2014 Jul-Dec;23(2)101-4. doi: $10.4103 / 0972-6748.151673$ [Crossref]
10. Batterham PJ, Christensen $H$, Mackinnon AJ. Modifiable risk factors predicting major depressive disorder at four year follow-up- a decision tree approach. BMC Psychiatry. 2009 Nov $22 ; 9 ; 75$.

doi: $10.1186 / 1471-244 X-9-75$ [Crossref]

11. Fiske A, Wetherell JL, Gatz M. Depression in older adults. Annu Rev Clin Psychol. 2009;5;363-89.

doi: $\quad 10.1146 /$ annurev.clinpsy.032408.153621 [Crossref]

12. O P Agarwal, S K Bhasin, P ChahabraK, et al. New Instrument(scale) for Measuring the Socio Economic Status of a Family- Preliminary Study. Indian J of Comm Med. 2005 Oct-Dec;30;111-4. [Crossref]

13. Grace G Aikman, Mary E Oehlert. Geriatric depression Scale long Form versus Short Form. Clinical Gerontologist. 2001;2(3-4)63-70. [Crossref]

14. Yesavage $J A$, Brink $T L$, Rose $T L$, Lum $O$, Huang $\mathrm{V}$, Adey $\mathrm{M}$, Leirer VO. Development and validation of a geriatric depression screening scale- a preliminary report. J Psychiatr Res. 1982-1983;17(1)37-49.

[Crossref]

15. Collin C, Wade DT, Davies S, Horne V. The Barthel ADL Index- a reliability study. Int Disabil Stud. $1988 ; 10(2) 61-3$.

[Crossref]

16. Kua EH, Ko SM. A questionnaire to screen for cognitive impairment among elderly people in developing countries. Acta Psychiatr Scand. 1992 Feb;85(2)119-22.

[Crossref]

17. Djernes JK. Prevalence and predictors of depression in populations of elderly- a review. Acta Psychiatr Scand. 2006 May;113(5)372-87. [Crossref]

18. Chou KL, Chi I. Prevalence and correlates of depression in Chinese oldest-old. Int J Geriatr Psychiatry. 2005 Jan;20(1)41-50.

[Crossref]

19. Zivin K, Llewellyn DJ, Lang IA, Vijan S, Kabeto MU, Miller EM, Langa KM. Depression among ol der adults in the United States and England. Am J Geriatr Psychiatry. 2010 Nov;18(11)1036-44. doi: $10.1097 /$ JGP.0b013e3181dba6d2 [Crossref] 
20. Taqui AM, Itrat A, Qidwai W, Qadri Z. Depression in the elderly does family system play a role?- $A$ cross-sectional study. BMC Psychiatry. 2007 Oct; $25 ; 7 ; 57$.

[Crossref]

21. Lai DW. Depression among elderly ChineseCanadian immigrants from Mainland China. Chin Med J (Engl). 2004 May;117(5)677-83.

[Crossref]

22. Nandi PS, Banerjee G, Mukherjee SP, Nandi S, Nandi DN. A study of psychiatric morbidity of the elderly population of a rural community in west bengal. Indian J Psychiatry. 1997 Apr;39(2)122-9.

[Crossref]

23. Lena A, Ashok K, Padma M, Kamath V, Kamath A. Health and social problems of the elderly- a cross-sectional study in udupi taluk, karnataka. Indian J Community Med. 2009 Apr;34(2)131-4. doi: 10.4103/0970-0218.51236 [Crossref]

24. Mitchell AJ, Subramaniam $H$. Prognosis of depression in old age compared to middle agea systematic review of comparative studies. Am J Psychiatry. 2005 Sep;162(9)1588-601. [Crossref]
25. Chapman D P, Perry G S, Strine T W. The Vital Link between Chronic disease and depressive disorders. Prev Chronic Dis. 2005 Jan;2(1)A-14. Available from: [Article] [Crossref]

26. Vinkers DJ, Gussekloo J, Stek ML, Westendorp $R G$, van der Mast RC. Temporal relation between depression and cognitive impairment in old ageprospective population based study. BMJ. 2004 Oct $16 ; 329(7471) 881$.

[Crossref]

27. Naveen Kumar D, Sudhakar T P. Prevalence of cognitive impairment and depression among elderly patients attending the medicine outpatient of a tertiary care hospital in South India. Int J Res Med Sci. 2013;1(14)359-364. [Crossref]

28. K Park. Park's Text Book of Preventive and Social Medicine. Baarsidas Bhanot. 22nd ed, $549 \mathrm{M} / \mathrm{s} 2013$.

[Crossref]

29. Anstey, Karin J , Von Sanden, Sargent-Coxet, al. Prevalence and risk factors for depression in a longitudinal population based study including individuals in the Community and Residential Care. The American Journal of geriatric Psychiatry. 2007;15(6)497-505.

[Crossref] 